\title{
Localization of laminin proteins during early follicular development in pig and rabbit ovaries
}

\author{
V. H. Lee ${ }^{1}$, J. H. Britt ${ }^{2}$ and B. S. Dunbar ${ }^{3}$ \\ ${ }^{1}$ Department of Cell Biology and Biochemistry, Texas Tech University, Health Sciences Center, \\ 3601 4th Street, Lubbock, TX 79430, USA; ${ }^{2}$ College of Veterinary Medicine, North Carolina State \\ University, Raleigh, NC 27606, USA; and ${ }^{3}$ Department of Cell Biology, Baylor College of Medicine, \\ One Baylor Plaza, Houston, TX 77030, USA
}

\begin{abstract}
Laminin, a major component of the basal lamina, is known to be important in the differentiation of epithelial cells. The outer granulosa cell layer of ovarian follicles is attached to a basal lamina surrounding the follicle and it has been demonstrated that proteins of the basal lamina can alter the steroidogenic capacity and cytoskeletal composition of mature granulosa cells. The present studies were carried out to evaluate the developmental expression of laminin proteins in the basal lamina of ovarian follicles during early stages of granulosa cell differentiation. Ovaries from sexually immature pigs (0-20 weeks of age) and rabbits ( $0-12$ weeks of age) were used for this study because formation of primordial follicles and initiation of follicular growth occur partialiy or completely postnatally. Specific antibodies were made against laminin $\beta 1 / \gamma 1$ chains using protein purified by high resolution two-dimensional polyacrylamide gel electrophoresis. These antibodies were used in immunohistochemical localization studies to demonstrate that laminin is associated with the basal lamina surrounding egg clusters and their connections to the ovarian surface epithelium and ovarian rete during early ovarian development. In addition, laminin was observed to associate with a continuous matrix that surrounds forming primordial follicles as they are isolated from the egg clusters. Laminin is localized in the basal lamina of primordial, primary, secondary, and tertiary follicles of both pig and rabbit ovaries. Laminin proteins are not only expressed throughout early follicular development in pigs and rabbits, but are also found surrounding the germ cell compartments prior to initiation of meiosis and formation of primordial follicles. These results demonstrate that laminin proteins are deposited in the basal lamina well before granulosa cells undergo morphological differentiation. This pattern of expression suggests that laminin proteins alone do not control changes in granulosa cell morphology during early development but may be required to maintain cell lineage commitment.
\end{abstract}

\section{Introduction}

Laminin, a large noncollagenous glycoprotein consisting of three disulfide-bonded polypeptide chains $\left(\alpha 1=M_{\mathrm{r}} 440000\right.$, $\beta 1=M_{\mathrm{r}} 220000$, and $\gamma 1=M_{\mathrm{r}} 220000$ ), is a constitutive protein of basal laminae in mammalian tissues (Rohde et al., 1979; Timpl et al., 1979, Burgeson et al., 1994). This protein complexes with fibronectin, collagen type IV, heparan sulfate proteoglycans, and other proteins to form the architectural foundation on which nearly all epithelial cells attach. Although these matrices were initially thought to have a role primarily in structural support, recent studies have shown that extracellular matrix components of the basal lamina are also important in maintaining cellular morphology, function and differentiation (Reid and Jefferson, 1984; Hadley et al., 1985; Enders et al., 1986; Ailenberg et al., 1988; Laurie et al., 1989). Binding of

Received 7 March 1996 laminin to specific cell membrane receptors has been found to regulate biochemical properties of most epithelial cells (Laybourn et al., 1989; Mecham, 1991; Nicosia et al., 1994). Many of these integrin and nonintegrin laminin receptors bind to amino acid sequences of $\beta 1$ and $\gamma 1$ chains in the laminin molecule or the carboxy-terminal end (E8 fragment) which includes portions of $\alpha 1, \beta 1$ and $\gamma 1$ chains (Mecham, 1991).

Ovarian follicular development involves maturation of oocytes as well as morphological and biochemical differentiation of granulosa cells (Hirshfield, 1991a). The outer layer of granulosa cells in the mammalian ovarian follicle is closely associated with the surrounding basal lamina as follicles grow and develop (Hirshfield, 1991a). Oogonia proliferate initially by mitosis, enter meiosis, and pause in prophase I (Buccione et al., 1990). A primordial follicle is formed (follicle assembly) when a squamous layer of granulosa cells and a basal lamina surround individual primary oocytes (Byskov and Hoyer, 1994). Folliculogenesis continues when oocytes begin to grow, granulosa 
cells undergo morphological differentiation and proliferation, and the basal lamina expands around enlarging follicles. Throughout folliculogenesis, a basal lamina is apparent between the outer layer of granulosa cells and the inner layer of theca cells. Previous studies of immunohistochemical localization have shown that laminin is present in the basal lamina surrounding primordial follicles and separating granulosa and theca interna layers of growing rat follicles after morphological differentiation of granulosa cells (Palotie et al., 1984). However, to date, there are limited studies of laminin protein expression during the earlier stages of follicular assembly in sexually immature mammalian ovaries.

Here we describe the temporal and spatial patterns of laminin proteins in sexually immature pig and rabbit ovaries. These species were chosen because, as opposed to most laboratory animals, assembly of follicles and the initiation of folliculogenesis occurs over an extended period after birth (Byskov and Hoyer, 1994). Ovaries from postnatal animals can be easily collected and the early stages of folliculogenesis evaluated (Lee and Dunbar, 1993; Morbeck et al., 1993).

\section{Materials and Methods}

\section{Laminin antibody peparation and characterization}

Laminin proteins extracted from mouse Engelbreth-HolmSwarm (EHS) matrix (Sigma, St. Louis, MO) were used to prepare specific antibodies to the combined laminin $\beta 1$ and $\gamma I$ chains. Laminin $\beta 1 / \gamma I$ chains were separated from the $\alpha I$ chains by high resolution two-dimensional SDS-PAGE and visualized by Coomassie brilliant blue (Sigma). The purified $200 \mathrm{kDa}$ protein band representing combined $\beta 1 / \gamma 1$ chains was excised from Coomassie-stained gels and silver-stained gels were used to verify the purity of proteins. Specific antisera against laminin $\beta 1 / \gamma I$ chains were produced in female guineapigs (Sasco, Omaha, NE) using methods described by Lee and Dunbar (1993). Female guinea-pigs were immunized intradermally with an emulsion of $0.5 \mathrm{ml}$ complete Freund's adjuvant (CFA, Gibco/BRL, Gaithersburg, MD) and $0.5 \mathrm{ml}$ PBS containing approximately $100 \mu \mathrm{g}$ laminin $\beta I / \gamma I$ chain proteins in the polyacrylamide matrix excised from two-dimensional SDSPAGE gels. Control animals received an equal volume of PBS:CFA (1:1) alone. These antibodies were characterized on one-dimensional PAGE immunoblots of total laminin proteins.

\section{Protein electrophoresis and immunoblotting techniques}

Laminin proteins were solubilized for SDS-PAGE according to the method described by Lee and Dunbar (1994) for immunoblot analysis. Samples for purification were separated by two-dimensional SDS-PAGE and visualized by Coomassie blue staining (Dunbar, 1987). Laminin protein samples for immunoblots were separated by one-dimensional SDS-PAGE on $7.5 \%$ acrylamide gels and transferred to Immobilon-P PVDF membrane (Millipore Corp., Bedford, MA). Transfers were blocked in Tris buffered saline (TBS, $0.01 \mathrm{~mol}$ Tris base $\mathrm{l}^{-1}$, $0.9 \%(\mathrm{w} / \mathrm{v}) \mathrm{NaCl}, \mathrm{pH} 7.5)$ containing $5 \%(\mathrm{w} / \mathrm{v})$ milk proteins, and probed with a 1:500 dilution of antiserum against laminin $\beta 1 / \gamma 1$ chains. Antibodies were detected with ${ }^{125}$ I-labelled protein A (ICN, Irvine, CA) and autoradiography.

\section{Tissue collection and preparation for immunohistochemistry}

Ovaries were collected from 1-, 35-, 70- and 140- day-old pigs, and 5-, 14-, 28-, 42-, 56-, and 84-day-old New Zealand White rabbits, and prepared for immunohistochemistry. The pigs were a four-way cross of Large White $\times$ Landrace (maternal) and Hampshire $\times$ Duroc (paternal) from the North Carolina Agricultural Research Service Herd and the rabbits were a New Zealand White strain obtained from a local rabbitry (Ray Nichols Rabbitry, Lumberton, TX). Six animals were used for ovarian samples from pigs (1-day-old) and rabbits (5-day-old), while three animals from each age were used for all other samples. The ages for ovary collection were chosen to provide samples with progressively mature populations of oocytes and follicles (Lee and Dunbar, 1993; Morbeck et al., 1993). Ovarian tissue was cut into $3-5 \mathrm{~mm}$ pieces and fixed in $4 \%(\mathrm{w} / \mathrm{v})$ paraformaldehyde/PBS for $30 \mathrm{~min}$ on ice. Tissues were subsequently washed three times in 50\% ethanol and three times in $70 \%$ ethanol on ice. Tissues were stored in $70 \%$ ethanol at $4^{\circ} \mathrm{C}$ overnight, dehydrated, and embedded in paraffin wax (Fisher Scientific, Houston, TX). Sections $(5 \mu \mathrm{m})$ were cut on a standard microtome, placed on acid cleaned microscope slides, and stored at room temperature until used.

\section{Immunohistochemistry}

Paraffin wax sections of the ovaries were probed with guinea-pig anti-laminin serum using the Vectastain $A B C$ Kit (Vector Laboratories, Burlingame, CA) (Lee and Dunbar, 1993). Briefly, sections of ovaries were deparaffinized, rehydrated and treated with $0.3 \%(v / v) \mathrm{H}_{2} \mathrm{O}_{2}$ in methanol for $20 \mathrm{~min}$ to quench endogenous peroxidases. Incubation with $0.025 \%(\mathrm{w} / \mathrm{v})$ pepsin in $0.01 \mathrm{~mol} \mathrm{HCl} \mathrm{l}^{-1}$ for $45 \mathrm{~min}$ at room temperature was used to unmask antigenic sites of extracellular laminin in the basal lamina (Forster et al., 1984). Slides were then treated with normal goat serum for $30 \mathrm{~min}$ and incubated with guinea-pig anti-laminin serum (1:500 dilution in PBS buffer containing 10\% BSA) overnight at $4^{\circ} \mathrm{C}$. After three washes in PBS, tissues were incubated with biotinylated goat anti-guinea-pig IgG for $30 \mathrm{~min}$ and washed with PBS. Slides were then incubated with the Avidin-Biotin reagent for $30 \mathrm{~min}$, washed three times with PBS, and labelled with $0.05 \%(\mathrm{w} / \mathrm{v})$ diaminobenzidine hydrochloride and $0.01 \%(\mathrm{v} / \mathrm{v})$ hydrogen peroxide for $5 \mathrm{~min}$. The reaction was stopped by rinsing with $\mathrm{H}_{2} \mathrm{O}$ and labelling was examined on a Nikon Labophot microscope. Controls consisted of serum from guinea-pigs immunized with CFA alone or preadsorption of guinea-pig anti-laminin serum with laminin protein $\left(1,5\right.$, and $\left.10 \mu \mathrm{g} \mathrm{ml}^{-1}\right)$. The morphology of ovarian tissue was examined by staining adjacent sections of ovaries with two common histological stains which illustrate the presence of glycoproteins or collagen fibres. Periodic acidSchiff stain was used to visualize for glycoproteins by the method of Sheenan and Hrapchak (1980). The basal lamina, Call-Exner bodies, and zona pellucida of growing follicles contain glycoproteins that stain with this procedure. Gomori's trichrome stain was used to visualize collagen (Lillie and 

2

kDa

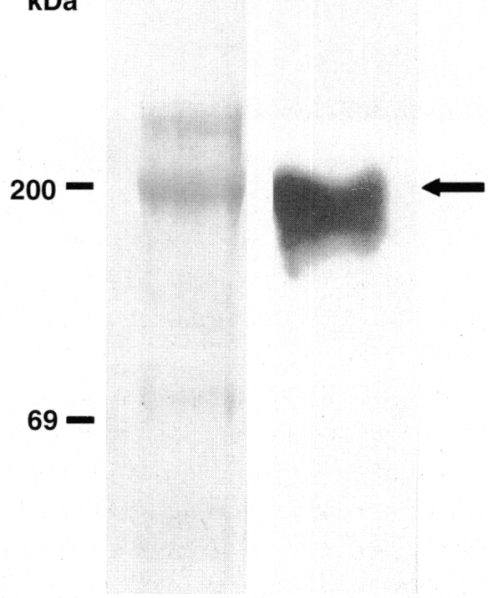

Fig. 1. Characterization of antibodies to laminin. One-dimensional PAGE Coomassie blue-stained gel (lane 1) and immunoblot (lane 2) of purified laminin proteins isolated from Engelbreth-Holm-Swarm tumour matrix ( 5 and $1 \mu \mathrm{g}$, respectively). The guinea-pig anti-laminin $\beta I / \gamma 1$ serum recognized a protein band migrating at approximately $200 \mathrm{kDa}$ (arrow), which corresponds to the molecular mass of laminin $\beta 1$ and $\gamma 1$ chains, but laminin $\alpha 1$ chains $(400 \mathrm{kDa})$ were not detected. The laminin $\beta 1 / \gamma 1$ subunits are not separated from one another by this method.

Fullmer, 1976). These stains are best observed in colour and are not reproducible in black and white photomicrographs; therefore this information will be described in the results where appropriate.

\section{Results}

\section{Development and characterization of laminin $\beta 1 / \gamma 1$ antibodies}

Antiserum made against laminin $\beta 1 / \gamma 1$ chains purified from the EHS tumour matrix by two-dimensional PAGE recognized the laminin $\beta 1 / \gamma I$ chain proteins on immunoblots when separated by one-dimensional PAGE (Fig. 1). On $7.5 \%$ acrylamide gels, laminin $\beta 1$ and $\gamma 1$ chains migrate as a single band at approximately $200000 M_{\mathrm{r}}$ and laminin $\alpha 1$ chain migrates at $400000 M_{\mathrm{r}}$. This antiserum did not demonstrate any crossreactivity with other extracellular matrix proteins, collagen type IV, or fibronectin (data not shown). To demonstrate these antibodies would recognize laminin proteins in the basal lamina of ovarian follicles, this antiserum was used to localize the site of deposition of laminin $\beta 1 / \gamma 1$ chains in the large antral follicles of pigs (Fig. 2a, b). Laminin labelling was observed in the basal laminae of ovarian follicles and endothelial cell of blood vessels in the perifollicular region. No labelling was detected in control ovaries probed with guinea-pig serum from CFA immunized animals (Fig. 2c) or with serum preadsorbed with purified laminin proteins.

\section{Laminin protein distribution in developing pig and rabbit ovaries}

The spatio-temporal pattern of laminin $\beta 1 / \gamma 1$ localization will be described in three sections organized according to the
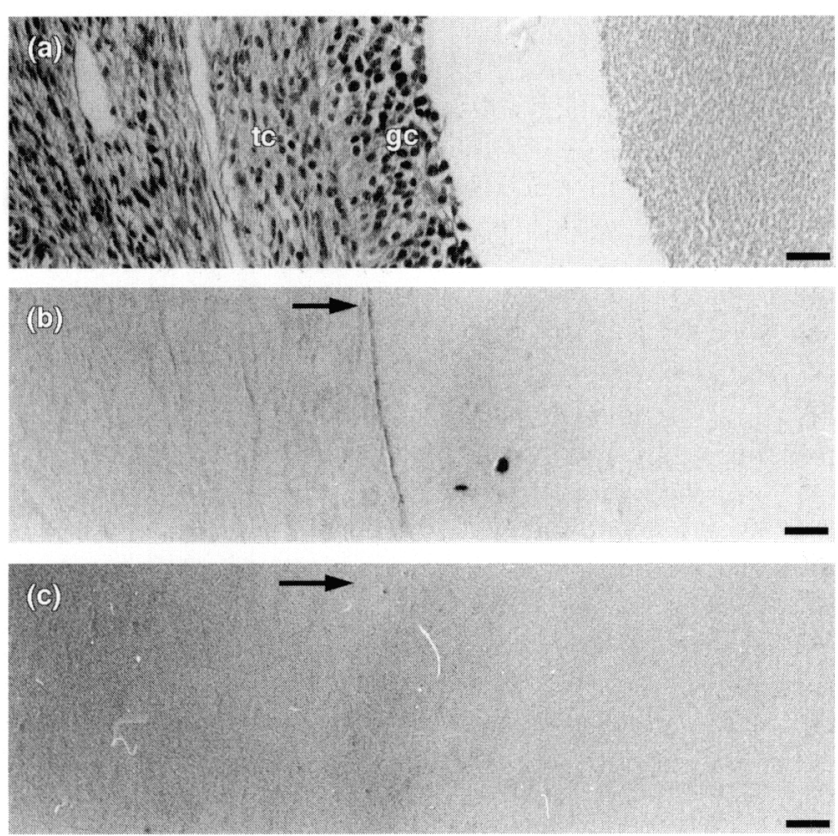

Fig. 2. Morphology and immunohistochemical localization of laminin in ovarian sections of a 140-day-old pig. (a) Photomicrograph of a section stained by the periodic acid-Schiff method to demonstrate the morphology of the antral follicle. (b) Photomicrograph of a section adjacent to (a) probed with guinea-pig anti-laminin $\beta 1 / \gamma 1$ serum (1:500). The basal lamina of the antral follicle contains a positive signal for laminin $\beta 1 / \gamma 1$ (arrow). (c) Photomicrograph of a section adjacent to (b) probed with serum from a guinea-pig immunized with complete Freund's adjuvant as a negative control (1:500). Note the lack of labelling at the comparable site (arrow) in the follicular basal lamina. gc, granulosa cells; tc, thecal cells. Scale bars represent $43 \mu \mathrm{m}$.

stage of ovarian development relative to follicle populations that are present. These results will be presented for each species individually and major similarities or differences emphasized. Follicles were classified according to the criteria of Erickson et al. (1985) as follows: primordial follicles contain squamous granulosa cells, primary follicles contain a single cuboidal layer of granulosa cells, secondary follicles contain two or more layers of granulosa cells, and tertiary follicles contain an antrum.

\section{Laminin localization in neonatal ovaries}

Pig ovaries. The 1-day-old pig ovary contains numerous oogonia organized in germ cell 'nests' called egg clusters (Maitland and Ullmann, 1993) which are located in the cortical region of the ovary adjacent to the ovarian surface epithelium and extend into the medullary region of the ovary (Fig. 3a). These egg clusters contain oogonia in various stages of mitosis and primary oocytes that have entered meiosis and are awaiting incorporation into primordial follicles. The egg clusters are surrounded by a basal lamina which is positively labelled for laminin $\beta 1 / \gamma 1$ proteins (Fig. 3c). Small amounts of stromal tissue are present between the ovarian surface epithelium and the underlying egg clusters and separating the individual clusters, but the tunica albuginia is not developed. Collagen does not appear to be abundant, as determined by the lack of Gomori's trichrome stain in the stromal cell matrices in 

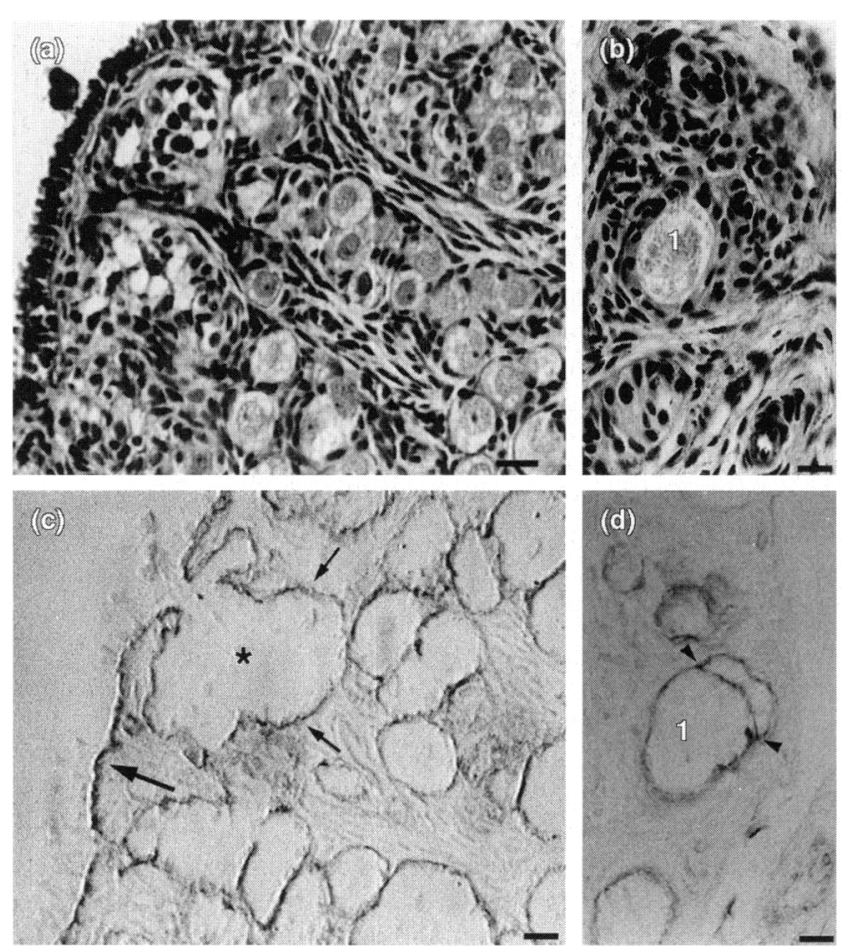

Fig. 3. Morphology and immunohistochemical localization of laminin $\beta I / \gamma I$ in neonatal pig ovaries. Photomicrographs of periodic acid Schiff stained ovarian sections from a 1-day-old pig (a,b). Photomicrographs of laminin $\beta 1 / \gamma 1$ localization in I-day-old pig ovaries (c, d). In (c) note the localization of laminin $\beta I / \gamma I$ in the basal lamina of the ovarian surface epithelium (large arrow) and the basal laminae (small arrows) surrounding the egg clusters $\left({ }^{*}\right)$ and primordial follicles. In (d) connection between a primary follicle (1) and the ovarian rete is illustrated (arrowheads). Scale bars represent (a, c) $21 \mu \mathrm{m}$ and (b, d) $15 \mu \mathrm{m}$.

the cortical region (data not shown). The tunica albuginea of the mature ovary consists of a collagenous connective tissue layer in the cortex immediately below the ovarian surface epithelium (Williams and Warwick, 1980). The 1-day-old pig ovarian surface epithelium is simple columnar (Fig. 3a) and the basal lamina, which is continuous with the underlying egg clusters at various sites, labels positive for laminin $\beta 1 / \gamma 1$ (Fig. 3c). In addition, connections on the medullary side of the cords are observed with the ovarian rete, which are also enclosed in a laminin $\beta 1 / \gamma 1$ positive basal lamina (Fig. 3b, d). Adjacent to the medullary side of the egg clusters, primary oocytes are separated and surrounded by a single layer of squamous grinulosa cells. Laminin $\beta 1 / \gamma 1$ labelling and the basal lamina are continuous around the primordial follicles and the egg clusters as follicles separate from these structures. Primary follicles, which contain a single cuboidal layer of granulosa cells with laminin $\beta 1 / \gamma 1$ localized in the basal lamina, are present in the medullary region of the pig ovary (Fig. 3b, d).

Rabbit ovaries. In 5-day-old rabbits, egg clusters extend deep into the medullary region with very little stromal tissue separating adjacent clusters (Fig. 4a). As in neonatal pig ovaries no tunica albuginea is observed in 5-day-old rabbit ovaries and collagen fibres are undetectable. Unlike in pigs, no primordial
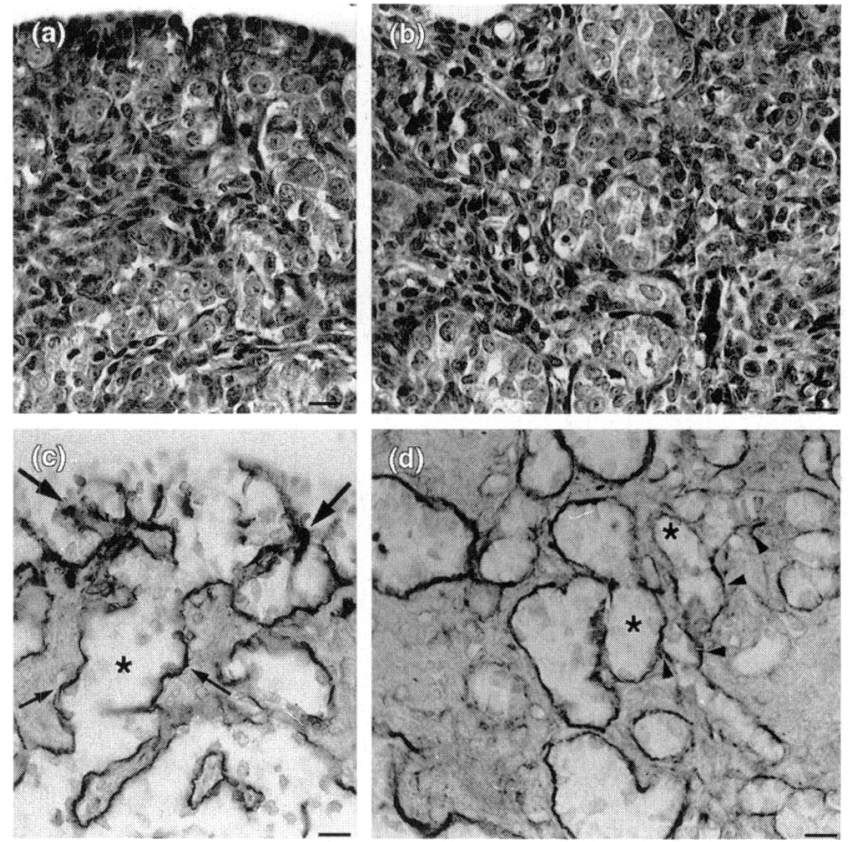

Fig. 4. Morphology and immunohistochemical localization of laminin $\beta 1 / \gamma 1$ in neonatal rabbit ovaries. (a, b) Photomicrographs of periodic acid-Schiff stained ovarian sections from 5-day-old rabbit. (c, d) Photomicrographs of laminin $\beta 1 / \gamma 1$ localization in 5-day-old rabbit ovaries. In (c) note the localization of laminin $\beta 1 / \gamma 1$ among the ovarian surface epithelium cells (large arrows) and the basal laminae (small arrows) surrounding the egg clusters $\left(^{*}\right\}$. In (d) connections of the egg clusters and ovarian rete are illustrated (arrowheads). Scale bars represent $15 \mu \mathrm{m}$.

follicles have formed at this stage of ovarian development. The 5-day-old rabbit ovarian surface epithelium consists of stratified columnar epithelial cells (three to five cells) that extend into the ovary between the egg clusters (Fig. 4a). An irregular laminin $\beta 1 / \gamma 1$ labelling pattern is located beneath the ovarian surface epithelium with a continuous matrix surrounding many of the peripheral egg clusters in the ovarian cortex (Fig. 4c). Physical connections, as indicated by a continuous laminin positive matrix, are present between both the ovarian surface epithelium on the cortical side of egg clusters and the ovarian rete in the medullary region of the ovary. Similarly, the rete are enclosed in a laminin $\beta I / \gamma 1$ positive basal lamina which is continuous with egg clusters at sites of contact (Fig. $4 \mathrm{~b}, d$ ). The 14-day-old rabbit ovary is comparable in composition to that of the 1-day-old pig, in that egg clusters are replaced with intervening stromal tissue and many primordial follicles. There is a well defined layer of laminin $\beta 1 / \gamma 1$ proteins beneath the ovarian surface epithelium and surrounding primordial follicles. The few remaining egg clusters have attachments to the ovarian surface epithelium and ovarian rete with continuous basal laminae which label positively for laminin $\beta 1 / \gamma 1$ proteins.

\section{Laminin localization during initial stages of follicle growth and differentiation}

Pig ovaries. At later stages of pig ovarian development (35-and 70-day-old) few oogonia remain and many individual 

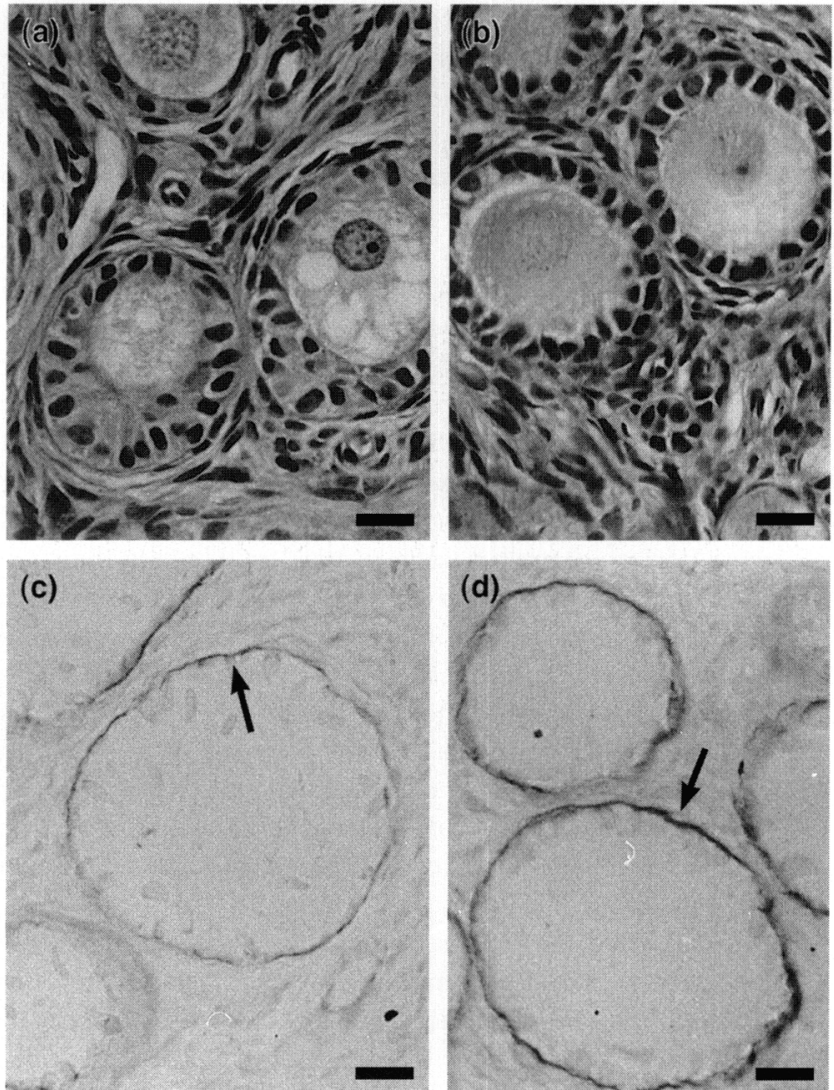

Fig. 5. Morphology and immunohistochemical localization of laminin $\beta I / \gamma I$ in growing follicles of pig and rabbit ovaries. Photomicrographs of periodic acid-Schiff stained ovarian sections from (a) 35-day-old pigs and (b) 28-day-old rabbits. Photomicrographs of laminin $\beta 1 / \gamma 1$ localization in (c) 35-day-old pig and (d) 28-day-old rabbit ovaries. Laminin $\beta 1 / \gamma 1$ is localized in basal laminae of growing follicles (arrows). Scale bars represent $21 \mu \mathrm{m}$.

primordial follicles are located in the periphery of the ovary. Laminin $\beta 1 / \gamma 1$ proteins are localized around primordial, primary, and growing follicles (Fig. 5a, c). Growing secondary follicles have numerous Call-Exner bodies which label positively for laminin $\beta 1 / \gamma 1$ proteins. Call-Exner bodies (see example in Fig. $7 \mathrm{~b}$ ) are spherical deposits of basal lamina matrix surrounded by granulosa cells and these structures have been observed in several species (Motta and Nesci, 1969; Leardkamolkarn and Abrahamson, 1992). The ovarian surface epithelium of pig ovaries at these ages is a simple cuboidal epithelium and the underlying basal lamina exhibits an uninterrupted pattern of laminin $\beta 1 / \gamma 1$ labelling. Gomori's trichrome stain indicates that collagen is abundant in the tunica albuginea between the ovarian surface epithelium and the irregular rows of primordial follicles (data not shown). The stromal tissue has proliferated and contains dense collagen bundles in the hilar region and between growing follicles. All these structures are enclosed by a basal lamina positive for laminin $\beta 1 / \gamma 1$ proteins.

Rabbit ovaries. In 28-day-old animals, the most mature follicles present are primary follicles (Fig. 5b) and in 42-day-old
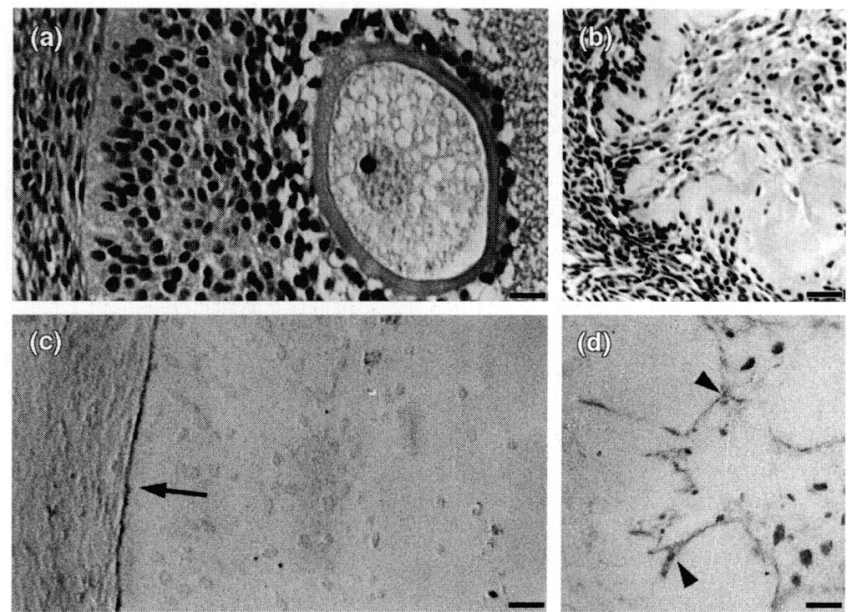

Fig. 6. Morphology and immunohistochemical localization of laminin $\beta I / \gamma I$ in tertiary and atretic follicles of pig ovaries. $(a, b)$ Photomicrographs of periodic acid-Schiff stained ovarian sections from 140day-old pigs. (c, d) Photomicrographs of laminin $\beta 1 / \gamma 1$ localization in 140 -day-old ovaries. Laminin $\beta I / \gamma 1$ proteins are localized in the basal lamina (arrow) of the tertiary follicle. Laminin $\beta 1 / \gamma 1$ proteins are also localized in the extracellular matrices of atretic follicles (arrowheads). Scale bars represent $(\mathrm{a}, \mathrm{c}) 21 \mu \mathrm{m}$ and $(\mathrm{b}, \mathrm{d}) 43 \mu \mathrm{m}$.

animals, both primary and secondary follicles are found within the outer layers of cortex, where many primordial follicles are located. Primordial and all growing follicles are enclosed in a complete basal lamina which is laminin $\beta 1 / \gamma 1$ positive (Fig. $5 \mathrm{~d}$ ). Laminin $\beta 1 / \gamma 1$ labelling is localized diffusely in the intercellular spaces of thecal cell layers surrounding secondary follicles (see example in Fig. 7c). As in the 35-day-old pig ovary, Call-Exner bodies (see example in Fig. 7b) appear in the secondary follicles of 42-day-old rabbit ovaries, which have obtained at least three layers of granulosa cells.

\section{Laminin localization in antral and atrefic follicles}

Pig ovaries. In the 140-day-old ovary the majority of the ovarian space is occupied by large antral follicles, which are surrounded by laminin $\beta 1 / \gamma 1$ in the basal lamina (Fig. 6a, c). Primary and secondary follicles are concentrated near the base of the hilar region and, as indicated by Gomori staining, dense bundles of collagen are present in the tunica albuginea, the central hilar region, and between follicles. Laminin $\beta 1 / \gamma 1$ labelling patterns around some antral follicles are diffuse and extend into the intercellular spaces of the thecal layers (see example in Fig. 7c). Periodic acid-Schiff positive Call-Exner bodies are present in the larger secondary and antral follicles, and the matrix of the Call-Exner bodies is laminin $\beta 1 / \gamma 1$ positive as seen in rabbit follicles (see example in Fig. $7 \mathrm{~b}$ ). Numerous follicles at different stages of atresia contain pycnotic nuclei and are enclosed by a continuous layer of laminin $\beta 1 / \gamma 1$ proteins in the surrounding basal lamina. In more advanced stages of atresia, an inner necrotic region (cellular debris and proteinaceous matrix) is separated from external stromal region by a thick matrix that labels positively for laminin $\beta 1 / \gamma 1$ proteins (Fig. $6 \mathrm{~b}, \mathrm{~d}$ ).

Rabbit ovaries. The 56- and 84-day-old ovaries contain primordial follicles in rows of three to five in the cortex and 


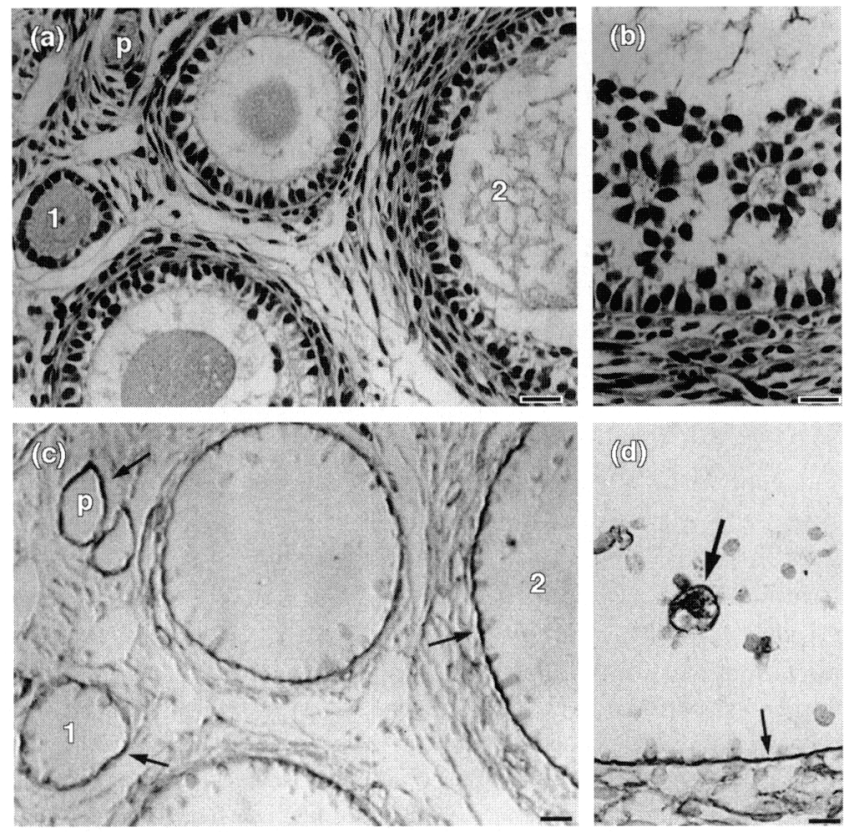

Fig. 7. Morphology and immunohistochemical localization of laminin $\beta 1 / \gamma 1$ in growing follicles and Call-Exner bodies of rabbit ovaries. (a, b) Photomicrographs of periodic acid-Schiff stained ovarian sections from 84-day-old rabbits. (c, d) Photomicrographs of laminin $\beta 1 / \gamma 1$ localization in 84-day-old rabbit ovaries. Laminin $\beta 1 / \gamma 1$ proteins are localized in the basal laminae of primordial, primary, and secondary follicles ( $c$, small arrows) and diffusely in the thecal layers surrounding growing follicles. Laminin $\beta 1 / \gamma 1$ proteins are localized in the basal lamina ( $\mathrm{d}$, small arrow) and the Call-Exner bodies ( $\mathrm{d}$, large arrow) of the tertiary follicle. p, primordial follicle; 1 , primary follicle; 2 , secondary follicle. Scale bars represent (a, c) $21 \mu \mathrm{m}$ and (b, d) $10 \mu \mathrm{m}$.

primary, secondary, and tertiary follicles (Fig. 7a). Laminin $\beta 1 / \gamma I$ proteins are detectable in the basal lamina of these follicles and the thecal cell layer intercellular spaces of secondary and tertiary follicles (Fig. 7c). Call-Exner bodies are present in the secondary and tertiary follicles, surrounded by a rosette of granulosa cells (Fig. 7b), and label positively for laminin $\beta I / \gamma 1$ proteins (Fig. $7 \mathrm{~d}$ ). In the 84 -day-old ovary, atretic follicles remain enclosed by a ring of laminin $\beta I / \gamma I$ positive matrix proteins throughout different stages of atresia. Atretic follicles contain a thickened layer of PAS positive matrix, which consists of laminin $\beta 1 / \gamma 1$ proteins surrounding the proteinaceous matrix in the centre, similar to that observed in pig ovaries (see example in Fig. 6b, d).

\section{Discussion}

These studies demonstrate that laminin proteins are localized in basal laminae surrounding egg clusters, growing follicles, and atretic follicles of sexually immature pigs and rabbits. Laminin is observed in the basal laminae of the ovarian surface epithelium and ovarian rete, which exhibit physical connections with egg clusters and forming follicles. Laminin has also been demonstrated in the ovarian follicular basal lamina of mice (Wordinger et al., 1983) and rats (Leardkamolkarn and Abrahamson, 1992). The present report extends those earlier findings in two nonrodent species and expands that information to include earlier stages of ovarian development prior to follicular assembly and morphological differentiation of granulosa cells.

Since laminin subunits are expressed and incorporated into basal laminae in correlation with developmental changes in many tissues, their presence is believed to convey specific signals for cellular differentiation and migration (Thomas and Dziadek, 1993; Vanden Heuvel and Abrahamson, 1993; Iredale and Arthur, 1994; Klinowska et al., 1994). It is possible that laminin in the basal lamina of ovarian follicles, along with other matrix molecules, supports the differentiation of granulosa cells. The present study was designed to determine whether laminin proteins appear simultaneously with morphological differentiation of granulosa cells in vivo or whether they are localized in the basal lamina prior to assembly of granulosa cells and primary oocytes into primordial follicles. We have used antibodies to specific laminin proteins to study early events of ovarian development with the pig and rabbit as models. Pigs and the rabbits were chosen because, unlike in mice and rats, early ovarian development, including follicular assembly and the initiation of meiosis in some or all of the oogonia, occurs over an extended period of time after birth (Byskov and Hoyer, 1994).

There are two proposed origins of granulosa cells: the ovarian surface epithelium and the ovarian rete, which are remnants of the mesonephric tubules. While neither cellular source has been proven to be the progenitor of granulosa cells, recent studies with neonatal rats by Hirshfield (1992) indicate that both of these structures may give rise to granulosa cells in the ovarian follicle. In the present study, on the cortical side of the egg clusters the surrounding layer of granulosa cells is found in close contact with the overlying ovarian surface epithelium at numerous sites in both pig (1-day-old) and rabbit (5-day-old) ovaries. Furthermore, laminin proteins are present at these sites in a continuous basal lamina connecting the ovarian surface epithelium and egg clusters. These results establish a physical connection through a continuous layer of laminin in the basal lamina between the ovarian surface epithelium and granulosa cells of the egg clusters in neonatal pig and rabbit ovaries. This arrangement supports earlier proposals that granulosa cells, at least in part, could arise and develop from the ovarian surface epithelium (Gondos, 1969). Similarly, in the medullary region, physical connections with egg clusters and the rete are observed with a continuous layer of laminin, which indicates continuity of the basal lamina between the cell compartments. Although these results are consistent with previous proposals of a dual source for granulosa cells, the proof remains elusive owing to the lack of specific cell markers that can be traced from the ovarian surface epithelium or rete tubules to the developing granulosa cells. Findings in neonatal rats demonstrate that expression of collagen type IV occurs in the presumptive granulosa cells of the egg clusters and may provide a marker for commitment of undifferentiated cells to the granulosa cell lineage (Rajah and Sundaram, 1994).

Follicle assembly is the organization of a primary oocyte, squamous granulosa cells, and a basal lamina into a primordial follicle (Hirshfield, 1991a). In neonatal pig and rabbit ovaries, the oogonia are arranged in clusters, retain their mitotic 
capacity, and are enclosed by a basal lamina. Primary oocytes that have completed their last mitotic division and entered meiosis are separated from the egg clusters and are enclosed by several squamous granulosa cells to form primordial follicles. In neonatal pig and rabbit ovaries, many primary oocytes located on the medullary side of egg clusters are partially enclosed by granulosa cells and a laminin-positive basal lamina. This arrangement gives the appearance that primordial follicles form by 'budding' from the egg clusters, carrying with them a surrounding layer of granulosa cells and a basal lamina. Thus, the basal lamina is formed around egg clusters and extends around the primordial follicle as it assembles. These studies therefore demonstrate that laminin and presumably other basal lamina proteins are associated with undifferentiated granulosa cells prior to follicular assembly and morphological transition into mature cuboidal granulosa cells.

The site of laminin protein synthesis for the follicular basal lamina has been proposed to be a combination of the granulosa and thecal cells because localization of laminin proteins has been demonstrated in secretory organelles of both of these cell types (Leardkamolkarn and Abrahamson, 1992). However, until reconstitution experiments like those carried out with Sertoli cells and testicular stroma studying the synthesis of the seminiferous tubule basal lamina (Skinner et al,, 1985) are carried out, this hypothesis cannot be tested. In the present study, laminin proteins were found to be localized in the basal lamina of forming primordial follicles, at a stage of development prior to any previous documented identification of theca cells in early follicles (Hirshfield, 1991b). Synthesis of basal lamina components during these early stages of follicular development could be explained by a number of theories. The laminin in the basal lamina of egg clusters and primordial follicles could be synthesized solely by the granulosa cells or by a combination of the granulosa cells and other stromal components. Studies of the developmental expression of mRNAs encoding individual laminin chains in the mouse embryo demonstrate that epithelial cells express laminin $\alpha 1, \beta 1$, and $\gamma 1$ chains, while laminin $\beta 1$ and $\gamma 1$ expression is more widely distributed in both epithelial and mesenchymal compartments (Thomas and Dziadek, 1993). The mRNA encoding collagen type IV, another component of the basal lamina, is expressed in the presumptive granulosa cells of egg clusters and the surrounding stromal cells in neonatal rat ovaries (Rajah and Sundaram, 1994). Alternatively, laminin synthesis could be dependent on early progenitors of the theca cells undetectable by current methods (Hirshfield, 1991b) and found in the mesenchymal tissue.

A further structural observation is the localization of laminin in the Call-Exner bodies of developing ovarian follicles. Call-Exner bodies have been defined as droplets of PASpositive material surrounded by rosettes of granulosa cells (Motta and Nesci, 1969). They were once thought to be fingerlike extensions of the antrum but serial sections through these structures demonstrated that they are isolated spheres of basal lamina proteins (Motta and Nesci, 1969). Laminin localization in the matrix of Call-Exner bodies has been demonstrated in rats (Leardkamolkarn and Abrahamson, 1992). The function of these structures remains unknown but the present study shows that they are numerous in growing secondary and antral follicles of both the pig and rabbit ovaries. These islands of laminin proteins have been used to verify the ability of the granulosa cells to synthesize the basal lamina of the follicle (Leardkamolkarn and Abrahamson, 1992). Thus, granulosa cells contain the ability to synthesis basal lamina proteins and may participate cooperatively with thecal or stromal cells to deposit the follicular basal lamina. In addition, the arrangement of granulosa cells in Call-Exner bodies illustrates the functional importance of the basal lamina in organizing the follicle, including the polarization and orientation of granulosa cells.

Laminin proteins are also localized in atretic follicles of pig and rabbit ovaries. The basal lamina has been found to be fragmented in atretic follicles using immunofluorescence and electron microscopy (Bagavandoss et al., 1983). Although the basal lamina appeared continuous by light microscopy in the present study, evaluation by electron microscopy would be required to verify this finding. The discrepancies in these two reports may be due to differences in the species, ages or hormonal manipulation of animals used.

The present study indicates that the association of laminin with developing follicles occurs throughout early development of the ovary and early granulosa cell differentiation. Furthermore, laminin is expressed throughout maturation of follicles and remains localized in the extracellular matrix of atretic follicles. Since laminin and other basal lamina proteins are associated with granulosa cells throughout the life of the follicle, the presence of these extracellular molecules may maintain the cell lineage commitment during different stages of granulosa cell differentiation. The interaction of the granulosa cells with the matrix may be directed by the differential expression of laminin receptors and integrins, which specifically bind to various molecules of the basal lamina. The interactions of laminin and other components of the basal lamina with granulosa cells of developing follicles provide an intriguing model for the regulation of early folliculogenesis.

This work was funded in part by grants to V. H. Lee from the United States Department of Agriculture 91-37203-6679 and B. S. Dunbar from the Mellon Foundation. The authors thank L. Hopkins for assistance with the histological preparation and T. E. Davey for preparation of photographic materials.

\section{References}

Ailenberg M, Tung PS, Pelletier M and Fritz IB (1988) Modulation of Sertoli cell functions in the two-chamber assembly by peritubular cells and extracellular matrix Endocrinology 122 2604-2618

Bagavandoss P, Midgley AR and Wicha M (1983) Develpmental changes in the ovarian follicular basal lamina detected by immunofluorescence and electron microscopy Journal of Histochemistry and Cytochemistry 31 633-640

Buccione R, Schroeder AC and Eppig JJ (1990) Interactions between somatic cells and germ cells throughout mammalian oogenesis Biology of Reproduction 43 543-547

Burgeson RE, Chiquet M, Deutzmann R, Ekblom P, Engel J, Kleinman H, Martin GR, Meneguzzi G, Paulsson M, Sanes J, Timpl R, Tryggvason K, Yamada $Y$ and Yurchenco PD (1994) A new nomenclature for the laminins Matrix Biology 14 209-211

Byskov AG and Hoyer PE (1994) Embryology of mammalian gonads and ducts In The Physiology of Reproduction pp 487-540 Eds E Knobil and JD Neill. Raven Press, New York

Dunbar BS (1987) Sample preparation for electrophoresis. In Two-dimensional Electrophoresis and Immunological Techniques pp 47-63. Plenum Press, New York 
Enders GC, Henson JH and Millette CF (1986) Sertoli cell binding to isolated testicular basement membrane Journal of Cell Biology 103 1109-1119

Erickson GF, Magoffin DA, Dyer CA and Hofeditz C (1985) The ovarian androgen producing cells: a review of structure/function relationships Endocrine Reviews 6 371-399

Forster SJ, Talbot IC and Critchley DR (1984) Laminin and fibronectin in rectal adenocarcinoma: relationship to tumour grade, stage and metastasis British Journal of Cancer 50 51-61

Gondos B (1969) Ultrastructure of the germinal epithelium during oogenesis in the rabbit Journal of Experimental Zoology 172 465-480

Hadley MA, Byers SW, Suarez-Quian CA, Kleinman HK and Dym M (1985) Extracellular matrix regulates Sertoli cell differentiation, testicular cord formation, and germ cell development in vitro Journal of Cell Biology 101 $1511-1522$

Hirshfield AN (1991a) Development of follicles in the mammalian ovary International Review of Cyfology 124 43-101

Hirshfield AN (1991b) Theca cells may be present at the onset of follicular growth Biology of Reproduction 44 1157-1162

Hirshfield AN (1992) Heterogeneity of cell populations that contribute to the formation of primordial follicles in rats Biology of Reproduction 47 466-472

Iredale JP and Arthur MJP (1994) Hepatocyte-matrix interactions Gut 35 729-732

Klinowska TCM, Ireland GW and Kimber SJ (1994) A new in vitro model of murine mesoderm migration: the role of fibronectin and laminin Differentiation 57 7-19

Laurie GW, Horikoshi S, Killen PD, Segui-Real B and Yamada Y (1989) In situ hybridization reveals temporal and spatial changes in cellular expression of mRNA for a laminin receptor, laminin, and basement membrane (type IV) collagen in the developing kidney Journal of Cell Biology 109 1351-1362

Laybourn KA, Hiserodt JC and Varani J (1989) Laminin receptor expression on murine tumor cells: correlation with sensitivity to natural cell-mediated cytotoxicity International Journal of Cancer 43 737-742

Leardkamolkarn V and Abrahamson DR (1992) Immunoelectron microscope localization of laminin in rat ovarian follicles Anatomical Record 233 41-52

Lee VH and Dunbar BS (1993) Developmental expression of the $55 \mathrm{Kd}$ zona pellucida protein and messenger RNA in ovarian follicles Developmental Biology 155 371-382

Lee VH and Dunbar BS (1994) Sample preparation for protein electrophoresis and transfer. In Protein Blotting: A Practical Approach pp 87-103 Ed. BS Dunbar. IRL Press, Oxford

Lillie RD and Fullmer M (1976) Histopathologic Technic and Practical Histochemistry pp 701-702. McGraw-Hill, New York

Maitland P and Ullman SL (1993) Gonadal development in the opossum, Monodelphis domestica: the rete ovary does not contribute to the steroidogenic tissues Journal of Anatomy 183 43-56
Mecham RP (1991) Laminin receptors Annual Review of Cell Biology 7 71-91

Morbeck DE, Flowers WL and Britt JH (1993) Response of porcine granulosa cells isolated from primary and secondary follicles to FSH, 8-bromo-cAMP and epidermal growth factor in vitro Journal of Reproduction and Fertility 99 577-584

Motta $\mathbf{P}$ and Nesci E (1969) The Call and Exner bodies of mammalian ovaries with reference to the problem of rosette formation Archives of Anatomical Microscopy and Morphological Experiment 58 283-290

Nicosia RF, Bonanno E, Smith M and Yurchenco P (1994) Modulation of angiogenesis in vitro by laminin-entactin complex Developmental Biology 164 197-206

Palotie A, Peltonen L, Foidart JM and Rajaniemi H (1984) Immunohistochemical localization of basement membrane components and interstitial collagen types in preovulatory rat ovarian follicles Collagen Related Research 4 279-287

Rajah R and Sundaram GS (1994) Protein distribution and gene expression of collagen type IV in the neonatal rat ovary during follicle formation Cellular and Molecular Biology 40 769-780

Reid LM and Jefferson DM (1984) Cell culture studies using extracts of extracellular matrix to study growth and differentiation in mammalian cells. In Mammalian Cell Culture pp 239-280 Ed. J Mather. Plenum Press, New York

Rohde H, Wick G and Timpl R (1979) Immunochemical characterization of the basement membrane glycoprotein laminin European Journal of Biochernistry 102 195-201

Sheenan DC and Hrapchak BB (1980) Theory and Practice of Histotechnology p 166. CV Mosby Company, St. Louis

Skinner MK, Tung PS and Fritz IB (1985) Cooperativity between Sertoli cells and testicular peritubular cells in the production and deposition of extracellular matrix components Journal of Cell Biology 100 1941-1947

Thomas T and Dziadek M (1993) Genes coding for basement membrane glycoproteins laminin, nidogen, and collagen IV are differentially expressed in the nervous system and by epithelial, endothelial, and mesenchymal cells of the mouse embryo Experimental Cell Research 208 54-67

Timpl R, Rohde H, Robey PG, Rennard SL, Foidart JM and Martin GR (1979) Laminin - a glycoprotein from basement membranes Journal of Biological Chemistry 254 9933-9937

Vanden Heuvel GB and Abrahamson DR (1993) Quantitation and localization of laminin A, B1, and B2 chain RNA transcripts in developing kidney American Journal of Physiology 265 F293-F299

Williams PL and Warwick R (1980) Splancnology. In Gray's Anatomy 36th Edition p 1424. WB Saunders Company, Philidelphia

Wordinger RJ, Rudick VL and Rudick MJ (1983) Immunohistochemical localization of laminin within the mouse ovary Journal of Experimental Zoology $\mathbf{2 2 8}$ 141-143 